\title{
La humillación como una forma socialmente tolerada del mal moral*
}

Recibido: agosto 27 de 2017 | Aceptado: febrero 21 de 2018

DOI: 10.17230/co-herencia.15.29.2

\section{Liliana Cecilia Molina González**}

liliana.molina@udea.edu.co

\begin{abstract}
Resumen El mal moral se define como un conjunto de acciones intencionales por medio de las cuales se lesiona la dignidad humana y, por tanto, se explica por la negación de derechos. Sin embargo, el mal moral no consiste solo en una negación de derechos, sino también en una experiencia que involucra, entre sus estrategias, la humillación: ésta puede entenderse como una experiencia compleja que implica también al cuerpo. Este artículo afirma que la humillación, como práctica social, es una forma socialmente tolerada del mal moral que incita a la deshumanización de otras personas, produciendo sufrimiento moral. Además plantea la necesidad de pensar la dignidad desde el cuerpo y considerar el sufrimiento como un criterio indispensable para resistir ante prácticas deshumanizadoras.
\end{abstract}

\section{Palabras clave:}

Mal moral, daño, humillación, dignidad, cuerpo.

\section{Humiliation as a socially tolerated form of moral evil}

\begin{abstract}
Moral evil is a set of intentional actions by means of which human dignity is harmed and, therefore, it is explained by the denial of rights. However, moral evil not only supposes the denial of rights, but also an experience that involves, among other strategies, humiliation. This latter can be understood as a complex experience involving also the body. This article argues that humiliation, as a social practice, is a socially tolerated form of moral evil that incites dehumanization of others, causing moral suffering. This article also raises the need to approach dignity from the body perspective and to consider suffering as a paramount criterion to resist dehumanizing practices.
\end{abstract}

\section{Keywords:}

Moral evil, harm, humiliation, dignity, body.
* Este artículo es producto del proyecto de investigación "El mal moral y el perdón como posible respuesta ética ante el daño", aprobado para su financiación por el Comité para el desarrollo de la investigación (CODI-Acta 647 del 17 de septiembre de 2013), en el marco de la convocatoria programática en Ciencias sociales, humanidades y artes (2013), de la Universidad de Antioquia. Como trabajo de investigación está ligado al grupo de investigación Cultura, violencia y territorio, categoría B de Colciencias (Convocatoria 781 de 2017), del Instituto de Estudios Regionales (INER), de la Universidad de Antioquia.

** Profesora Asociada del Instituto de Filosofía de la Universidad de Antioquia, MedellínColombia. ORCID ID: 0000-0002-1760-5909 
Tradicionalmente el mal moral se sitúa en el contexto de la atrocidad y la crueldad, ${ }^{1}$ pues se refiere a una acción intencional dañina que viola los derechos humanos y, con ello, la dignidad de quienes son afectados por este tipo de acciones. Sus víctimas suelen estar en estado de indefensión y son sometidas a vejámenes que les restan o suprimen, según cada caso, autonomía y derechos, pero también la capacidad para responder ante el daño recibido. Sin embargo, el mal moral no se refiere solamente a acciones que al lesionar derechos y bienes afecten la autonomía y la dignidad, sino a una experiencia que produce sufrimiento y secuelas relacionadas con la ruptura de relaciones -con uno mismo, con los otros y con el mundo-, porque el daño que produce afecta la percepción de sí mismo como sujeto moral (Brison, 2003, pp. 2-21).

Suelen considerarse como ejemplos clásicos del mal moral los genocidios, las masacres, las violaciones en masa, y los experimentos no consentidos. Con el respaldo del discurso de los derechos humanos se aprende a reconocer que los casos mencionados son el ejemplo indiscutible del mal que intencionalmente podemos hacernos unos a otros; y gracias a ese discurso y a su sustento, así como al reconocimiento universal de la dignidad humana, resulta apremiante reflexionar, constantemente, sobre nuestra condición humana y sobre los retos que supone la vida en común con otros.

Sin embargo, se puede admitir que debido a las secuelas que el daño produce, el mal moral tiene lugar también en situaciones en las que opera la discriminación y exclusión del mundo social. Estos casos ejemplifican prácticas de humillación social pues involucran tanto un menoscabo de los derechos (bienes patrimoniales y extrapatrimoniales), como una experiencia compleja de sí mismo como sujeto moral. La humillación alude a una experiencia que no es enteramente privada ni enteramente descriptible en términos de una experiencia social: se trata de una experiencia que se puede

1 Sobre la atrocidad como paradigma del mal moral, cfr. Claudia Card $(2002,2010)$. Otras perspectivas sobre el mal moral se pueden consultar en Kant (1969), Arendt (1999, 2006, 2007) y María Pía Lara (2009). El aspecto común entre estos autores es la perspectiva secular y filosófica sobre el mal moral y político. La bibliografía sobre el mal moral es copiosa, pero remito a algunos que analizan el problema del mal de manera panorámica, además de los autores ya mencionados: Bernstein (2005), Revault (2010), AndersonGold \& Muchnik (2010), y Neiman (2012). 
explicar en términos de ruptura y de marginalización del mundo social, y como la percepción dolorosa de una imposibilidad o de una dificultad: la de que la propia vida no sea socialmente inteligible y por tanto posible, porque no encaja con los términos de una episteme y de una ontología social dominante (Butler, 2002; Ahmed, 2015).

Incluso en algunos casos esta dificultad puede convertir la posibilidad de la propia vida en ininteligible para quien padece los efectos sociales y simbólicos de la exclusión y la discriminación. Al respecto es pertinente mencionar los análisis de Judith Butler y Sara Ahmed, quienes coinciden en analizar el mundo social como un complejo de relaciones y de normas organizadas conforme a la producción de epistemes dominantes que circulan por medio de narraciones y prácticas, que dependen, a su vez, de una ontología socialmente producida. La ontología social está conformada por categorías, normas y prácticas a través de cuya reiteración se regula el mundo de las relaciones sociales, lo que produce, entre otros efectos, una discriminación entre vidas inteligibles y no inteligibles; estos últimos pueden ser llamados cuerpos marginados o cuerpos abyectos (Butler, 2002, pp. 14, 19, 20, 26, 38-39), pero también cuerpos odiados (Ahmed, 2015, pp. 87-95) y cuerpos repugnantes (Ahmed, 2015, p. 143), los cuales son excluidos del mundo de las relaciones sociales y políticas; o incluidos pero por medio de la exclusión que los produce como cuerpos y vidas despreciadas. El lenguaje cargado de emociones juega un papel importante en la producción de cuerpos abyectos, al hacer circular imaginarios sociales de odio y de exclusión que refuerzan la percepción de algunas subjetividades como cuerpos despreciables, es decir, como cuerpos que deben permanecer al margen de las posibilidades del mundo social o incluidos, pero en su condición de exclusión.

Por tanto, resulta fundamental preguntarse por las bases del respeto recíproco, por cómo resistirse a la deshumanización y degradación de otros; e interrogar por las motivaciones morales para defender el respeto recíproco, pues más allá de los clásicos escenarios del mal moral, como los antes mencionados, en el mundo social cada vez son más frecuentes situaciones y prácticas en las que se vulneran la dignidad o el valor moral intrínseco propio de cada uno, y no 
se reconoce la dignidad, la cual, según el discurso de los derechos humanos, es inherente a toda vida humana. En todos los escenarios del mal moral se viola, se transgrede, se suspende o se niega la dignidad humana. Es decir, los seres humanos, como individuos, o como parte de un grupo, son tratados de maneras deshumanizadoras y degradantes, siendo la humillación una de las estrategias de estos escenarios.

En efecto, cuando se intenta comprender la lógica de la humillación (el cómo), la experiencia de la humillación (los sentimientos, el sufrimiento) y los actores implicados (actor, paciente y espectador), se hace notable que su único escenario no son las situaciones atroces como los campos de concentración, las cámaras de tortura, las masacres o las violaciones en masa. Además, en el contexto de la vida en común se puede ver que la humillación en cuanto acción (experimentada por quien la padece), y como conducta y proceso (por parte de quienes la infligen y de quienes son sus espectadores), se presenta, muchas veces, como una práctica socialmente tolerada.

En este orden de ideas, los objetivos del presente artículo son (1) identificar algunos elementos que convierten la humillación en una práctica socialmente tolerada, y (2) considerar el papel de las emociones en nuestras prácticas morales, con el fin de interrogar, en las consideraciones finales, sobre la posibilidad de un enfoque necesario para reconocer que el respeto concreto de la dignidad humana precisa unas condiciones materiales, es decir, históricamente situadas. En la última sección se plantea por qué el "cuerpo" puede ser un punto de partida necesario para repensar la dignidad humana, pues el sufrimiento que involucra la discriminación entendida como una forma de humillación social, si bien produce un menoscabo de derechos produce también sufrimiento, y esta es una experiencia que involucra al cuerpo. ${ }^{2}$

2 Entendida como una práctica de humillación; si bien la discriminación alude a un menoscabo de derechos -y por eso reconocer en primera persona la humillación depende de la interiorización del discurso de los derechos humanos y del discurso sobre la dignidad que lo sustenta-, se necesita un enfoque adicional al de los derechos para situar de manera concreta, es decir, en contextos específicos, la exigencia del respeto de la dignidad humana, y para comprender la motivación para actuar moralmente. Este enfoque buscado puede ser el cuerpo, como se intenta mostrar al final del presente artículo. Este enfoque requiere un estudio sobre los efectos de las emociones en nuestra experiencia del mundo y queda como un asunto aún pendiente por desarrollar. 
Para cumplir con ambos objetivos, primero se plantean los enfoques con los cuales se puede comprender la humillación como una experiencia compleja no reducible a una experiencia privada, pero tampoco explicable solamente por el menoscabo de derechos ni acudiendo a principios abstractos como el de la autonomía y el de la dignidad. Luego se considera en qué sentido el lenguaje que circula cargado emocionalmente, junto con los imaginarios sociales, pueden propiciar prácticas de humillación social como la discriminación. Finalmente, se plantean algunas observaciones como punto de partida para seguir indagando por qué es necesario repensar la dignidad desde el cuerpo.

\section{Perspectivas posibles de enfoque y análisis}

Como señala Evelin Lindner (2009, p. 48), la humillación puede ser evaluada con diferentes perspectivas: la perspectiva de la víctima, la del testigo (espectador) y la del humillador, en cualquier combinación de estas variables, y desde la perspectiva de una práctica específica. Ahora bien, desde el punto de vista de la experiencia puede evaluarse como una experiencia privada y con un punto de vista psicológico, pero también como una experiencia relacional. Consideremos, por ejemplo, lo que sucede cuando se desvirtúa públicamente la capacidad intelectual de un estudiante (en la secundaria) porque no cumple con los cánones establecidos por los parámetros de la evaluación académica escolar; pero también lo que ocurre con estudiantes que optan por una orientación sexual no heterosexual. ${ }^{3}$ Los ejemplos pueden ser numerosos, pero en todo caso "sentirse humillado" remite a una experiencia compleja que puede ser descrita al mismo tiempo como privada y social, pues la humillación, añado, pone en juego la dimensión doble e inseparable de las emociones: es decir, su carga cognitiva y afectiva. En la explicación de autoras como Sara Ahmed (2015), el aspecto cognitivo de la emoción es

3 Uno de los casos más recientes respecto a la práctica social de la humillación como discriminación es el del suicidio del joven Sergio Urrego, muy documentado en la prensa nacional, cuya familia ha sido respaldada jurídicamente por la organización de defensa de los derechos humanos de las personas LGBT Colombia diversa. Al respecto remito a la publicación del equipo de redacción del periódico El Tiempo (2016), titulado "Aceptan delito de discriminación en caso de estudiante Sergio Urrego". 
inseparable de su aspecto afectivo; para ella no se trata de "crear esferas separadas entre la conciencia y la intencionalidad, por un lado, y las reacciones fisiológicas o corporales por el otro" (2015, p. 312). En The Promise of Happiness Ahmed aclara que:

El afecto es lo que pega o sostiene o preserva la conexión entre ideas, valores y objetos [...] Pienso que la distinción entre afecto y emoción puede describir de modo incompleto el trabajo de las emociones, el cual implica formas de intensidad, orientación corporal, y caminos que no se refieren simplemente a un "contenido subjetivo" o a la cualificación de una intensidad. Las emociones no son "después-de-los-pensamientos", más bien las emociones delinean la forma como se mueven los cuerpos en los mundos que habitan. (2010, p. 230)

Más adelante Ahmed añade que:

Aunque se pueda separar una respuesta afectiva de una emoción que se atribuye como tal (separar las sensaciones corporales del sentimiento de tener miedo), esto no significa que en la práctica, o en la vida diaria, ellas estén separadas. De hecho, son contiguas; se deslizan entre sí, se pegan y coinciden aun cuando estén separadas. El "afecto del miedo" puede estar separado del reconocimiento autoconsciente de tener miedo (el parpadeo en el rabillo del ojo señalando la presencia del extraño, que se registra como una alteración sobre la piel antes de que hayamos reconocido al extraño como extraño). Sin embargo, esto no significa que el "afecto miedo" sea autónomo. Antes de que seamos afectados, antes de que suceda algo que cree una impresión sobre la piel, las cosas ya están en un lugar que nos inclina a ser afectados de unos modos más que de otros. (2010, p. 231) ${ }^{4}$

Lindner (2009, p. 48) señala, por otro lado, que la experiencia de la humillación puede examinarse como un incidente individual, pero también como una práctica sistemática; como una herramienta de control social o una herramienta de dominación e incluso como una experiencia que puede activar la capacidad de resiliencia, es decir, nuestra capacidad para resolver positivamente experiencias traumáticas.

Como parte de las dinámicas sociales, la experiencia de la humillación puede suscitar emociones como ira, vergüenza, culpa, desamparo, miedo, angustia y deseo de venganza. Todas estas emociones tienen que ver con la afectación o pérdida de autonomía, con la

4 Las traducciones son de mi autoría. 
percepción de una falta de reconocimiento del propio valor moral (de un individuo o de un grupo) y, en algunos casos, con la lesión de la identidad y la experiencia de exclusión de la comunidad social, moral y política. En ese sentido, la humillación involucra una experiencia de sufrimiento y permite pensar que la ira y el resentimiento asociados a ella pueden entenderse como emociones morales (Lindner, 2009, pp. 51-52). Al respecto añado que, aunque el resentimiento y la ira puedan desencadenar comportamientos negativos e indeseables como la violencia o la agresión, funcionan también como sensores morales de nuestra humanidad cuando ésta se ve afectada, negada o amenazada. En ese sentido, resulta indudable que, como muchos autores subrayan, privar de estos sensores morales y emocionales a las personas afectadas por el daño, es como deshumanizarlos:

La ira de los que han sido brutalmente victimizados y humillados puede ser irracional, pero también puede ser una expresión de un sentimiento legítimo de indignación personal o política. Tradicionalmente, el resentimiento se ha visto como una emoción negativa que debe ser superada. Pero debemos ser capaces de distinguir las formas patológicas del resentimiento de aquellas que son el resultado del daño moral o político violento. (Bernstein, 2015, p. 263)

Como acción, la humillación produce daño, pues atenta contra la dignidad de una persona o de un grupo. Por su relación negativa con la dignidad -puesto que la lesiona-, un examen de la humillación como fenómeno social permite reflexionar, por una vía negativa, sobre el contenido que concedemos a una categoría como la de "dignidad" humana. Pero también nos permite reexaminar nuestras concepciones sobre el componente social de la condición humana, ya que ésta se gesta y gestiona o agencia en un mundo social donde las concepciones que conforman una episteme dominante pueden llegar a ser excluyentes y, en algunos casos, pueden llevar a legitimar prácticas de humillación, como la discriminación o la negación de derechos para grupos e individuos que no encajen en un ideal social normativo y dominante. ${ }^{5}$

5 Este tipo de fenómenos son los que algunos autores, como Judith Butler (2006), buscan desnaturalizar, analizando el carácter no pre-dado de nociones como las de cuerpo, género, masculino y femenino, lo humano, con las cuales se organiza el mundo social y, con ello, los límites de lo inteligible y, por tanto, nombrable o admisible como "real". 
Conforme a las observaciones anteriores, la palabra "humillación" remite al acto, al sentimiento y al proceso o práctica; es decir, al agente, al paciente y al espectador. Tres figuras que podemos separar analíticamente pero que pueden coincidir y ser inseparables en algunos casos. Con estas tres maneras de entender la palabra podemos identificar situaciones complejas y degradantes y formas de pensar o imaginarios sociales y políticos que legitiman prácticas de discriminación, que pueden llegar a degradar a otros seres humanos.

Ahora bien, siguiendo a Lindner, para indagar sobre la humillación como práctica socialmente tolerada se puede comenzar con las preguntas que ella misma plantea:

¿En qué consiste la experiencia de la humillación? ¿Qué sucede cuando una persona se siente humillada? ¿Cómo transforma la humillación la percepción de la justicia, el honor, la dignidad, el respeto y el autorrespeto? ¿Qué rol juega la globalización de los derechos humanos en la implementación de la humillación? ¿Cómo es percibida y cómo se responde a la humillación en diferentes culturas? ¿Qué se puede hacer para superar los efectos violentos de la humillación? (2009, p. 54)

Podemos agrupar estas preguntas en torno a tres tipos de cuestionamientos para definir enfoques y perspectivas de análisis, útiles para indagar por la humillación como una forma del mal moral que en algunos casos puede llegar a ser tolerada socialmente.

1. La pregunta por la experiencia de ser humillado, es decir, por el tipo de sufrimiento que implica la humillación, una experiencia que puede ser física y mental.

En esta perspectiva se sitúan Avishai Margalit (2010, pp. 77-79), quien describe la humillación como crueldad mental, y Wolfgang Sofsky (2006), quien afirma que no toda violencia consiste en la destrucción física, pues "el cuerpo no es una parte del hombre, sino su centro constitucional. Por eso el daño afecta por igual al alma y al espíritu, al yo y a la existencia social" (p. 65). En el horizonte de la pregunta por la experiencia de ser humillado, se puede incluir la pregunta por la relación entre humillación y otras emociones morales ${ }^{6}$ como rabia, vergüenza, culpa, resentimiento e indignación.

6 El criterio para hablar de emociones morales es su carácter cognitivo, es decir, se trata de emociones que no se entienden como estados fisiológicos, sino que están atravesadas y 
2. La pregunta por cómo la cultura (conjunto de reglas y prácticas de diversos tipos, relacionadas con tradiciones y concepciones del mundo social) permea y define qué acción se juzga como humillante. Por tanto, la cultura incide en la forma como se percibe o no, desde el sufrimiento, la experiencia de humillar y de ser humillado; pero también incide en el diseño de políticas de gobierno.

En este punto es pertinente mencionar la manera en que las tácticas de guerra y las políticas que la respaldan incluyen estrategias humillantes que se justifican políticamente y son toleradas socialmente, lo que contribuye a aniquilar moralmente (y físicamente) no solo "individuos" que se juzgan como "enemigos", sino la cultura y forma de vida que encarnan. Pues "cuando una vida se convierte en impensable o cuando un pueblo entero se convierte en impensable, hacer la guerra resulta más fácil” (Butler, 2011, p. 24). Y la guerra también busca aniquilar los rasgos que definen un grupo ya sean étnicos, religiosos o de otra índole. En esta perspectiva resultan útiles los análisis de Judith Butler, respecto de las prácticas de la tortura y la pregunta por la ética de la fotografía, pues con base en sus análisis afirma dos asuntos importantes: por un lado -citando a la periodista Joan Walsh- que "esta serie de imágenes de Abu Ghraib es solo una instantánea de las tácticas sistemáticas empleadas por Estados Unidos durante más de cuatro años de guerra global contra el terror" (Butler, 2010, p. 135). Y por otro, afirma que quienes tomaron las fotografías en la cárcel de Abu Ghraib y las pusieron a circular entre sus conocidos, no consideraron sus acciones como humillantes y degradantes, pues como ella señala: "Queda claro que estas imágenes fueron pasadas, disfrutadas, consumidas y comunicadas sin ir acompañadas del menor sentido de la indignación moral" (2010, p. 132).

Por otro lado, en este enfoque se puede incluir la pregunta por el papel reformador o no de los escarnios públicos, cuyo objetivo no es sancionar una acción, sino degradar, desprestigiar o estigmatizar a la persona responsable de una acción que contraría los diferentes tipos de normas que organizan el mundo social (Nussbaum, 2006, pp. 266-290).

sustentadas en juicios sobre el bien y el mal. En este sentido, de su contenido proposicional depende el tipo de relaciones que establecemos con los otros, con el mundo social y con uno mismo, actualizando o ejerciendo (y en otros casos, inmovilizando, debido a un daño, por ejemplo) la capacidad para actuar moralmente y en asociación con otros. 
3. La pregunta por el papel de la declaración de los derechos humanos universales en el reconocimiento de que algunas prácticas sociales y culturales son humillantes.

En este caso se pueden mencionar, por ejemplo, los debates sociales y académicos que ha suscitado la negación de derechos a parejas del mismo sexo. En sociedades como la nuestra ha habido una lucha por parte de los miembros de la comunidad LGBTI porque les sean reconocidos derechos sociales y económicos necesarios para una vida digna. Su lucha ha sido por derechos, pero también por el reconocimiento simbólico y social de la diversidad sexual como una opción de vida tan digna de ser valorada y respetada socialmente como la de las parejas heterosexuales. Su lucha manifiesta, por ejemplo, la necesidad de transformar imaginarios sociales y morales concernientes a quiénes y cómo puede estar constituida una familia.

Como se ha venido señalando, con prácticas sociales de humillación como la discriminación se tiende a normalizar la percepción deshumanizadora de personas y grupos, es decir, aquella según la cual algunas personas y grupos son "enfermos", "ciudadanos de segunda clase" e incluso "individuos incapaces de ser responsables". Ignorar y desvirtuar la posibilidad de ciertas vidas depende, en parte, de la normalización de prácticas socialmente aprobadas de humillación con las cuales se niega que un grupo de individuos, cuyas elecciones y formas de vida se juzgan como ajenas a los patrones de normalidad (que una sociedad considera encomiables), puedan ser reconocidos como parte suya.

¿Por qué la humillación puede ser considerada como una experiencia transversal a toda forma de mal moral, incluyendo maneras socialmente toleradas? Porque el daño que se produce como menoscabo de bienes morales, contemplados en el derecho como bienes extra-patrimoniales, causa perjuicio sobre los afectos y la vida de relación (como sucede en el caso de lesiones a la integridad personal que afectan directamente el honor y el autorrespeto). Además estos daños son experimentados como un sufrimiento que menoscaba, según el caso, la identidad y el autorrespeto, pues impide que un individuo o grupo pueda reconocerse como parte integral de una comunidad social.?

7 Sobre la conceptualización del daño moral hay una copiosa bibliografía disponible. 
Desde esta perspectiva se comprende por qué la humillación puede erosionar la confianza en los otros, en las instituciones y en las leyes, pues estas últimas pueden resultar insuficientes para garantizar y respaldar los derechos de quienes son socialmente excluidos, o para responder a su experiencia de sufrimiento y a sus secuelas: en su caso, la dignidad aparece como algo que es necesario construir y llenar de contenido material.

Sentirse humillado consiste, por tanto, en una experiencia compleja de exclusión que implica la negación de derechos, porque acarrea pérdida de autonomía; pero también involucra la negación de un reconocimiento social del propio valor moral, que causa sufrimiento. Cuando esto sucede, cuando el sentimiento de autorrespeto se ve menoscabado - pues depende del trato que otros nos otorgan, sean individuos o instituciones, es decir, cuando se ve amenazada, negada, impedida nuestra pertenencia al grupo de los seres humanos, o mejor aún, la posibilidad de nuestra condición humana-, entonces entramos en el escenario de la humillación.

Sin embargo, poder sentirse humillado depende, como señala Saulo Fernández Arregui (2008), de la interiorización del discurso de los derechos humanos:

la humillación solo surge en un contexto en el que el mensaje de los derechos humanos ha sido interiorizado [...] Cuando el trato recibido de los otros no se adecúa a la idea de la igualdad de dignidad y no hay racionalización posible que justifique la supremacía moral de unas personas sobre otras, el subyugado verá herida su dignidad, sintiendo entonces una emoción diferente a la deshonra (deshonor) y al miedo, que atenta contra la esencia misma de lo que una persona es o debería ser: la humillación [...] para sentir humillación en las propias carnes, primero es necesario que la víctima haya interiorizado el mensaje igualitario: del mismo modo que las mujeres del siglo Xv difícilmente se podían sentir humilladas por las prácticas machistas dominantes es difícil que se sientan humilladas las mujeres del siglo XXI que aún asumen un lugar subyugado al hombre como algo perteneciente al orden natural de las cosas. (2008, pp. 33-34)

Algunos textos son incluidos al final en las referencias bibliográficas. La pregunta por el daño moral y la reparación moral, a partir de la filosofía, es el eje de un proyecto actual de investigación a mi cargo como investigadora principal, titulado: "Daño moral. Una exploración sobre el carácter simbólico y narrativo de la reparación moral", aprobado para su financiación por el comité para el desarrollo de la investigación (CODI-Acta 748 de 2017), para el periodo 2017-2020, en el marco de la convocatoria programática en Ciencias sociales, humanidades y artes, 2016. 
Este sentimiento nace, sin embargo, de la combinación de dos aspectos: por un lado, habitamos en sociedades que defienden el contenido de los derechos humanos, pero, por otro lado, convivimos con viejas prácticas que los contradicen. Por citar un ejemplo, confundir dignidad con honor social, o con la adecuación a "patrones de normalidad" socialmente construidos y aceptados que pueden llevar a justificar una distribución desigual de la "dignidad" humana, es decir, una distribución diferenciada de derechos. Esta tendencia convierte en sujeto de derechos solo a algunos que tienen efectivamente la oportunidad de disfrutar de ellos. Además, los imaginarios sociales (como los del odio y los del miedo) se usan para incentivar la negación de derechos a comunidades o grupos que se alejan de los patrones de normalidad socialmente aceptados, o bien porque se perciben como cuerpos amenazantes o como cuerpos despreciables (Ahmed, 2015, p. 79). Estas prácticas sociales no se dan sin producir una discriminación diferencial de afectos, como sucede con las manifestaciones públicas de duelo ante el valor de las vidas que se consideran dignas de ser respetadas y la falta de duelo ante las vidas que no se consideran dignas de serlo, vidas que no son del todo reconocidas como vidas, y cuya pérdida no se lamenta (Butler, 2006a, pp. 16-17, 21, 36, 44-78). Que una vida o una cultura y su forma de vida se conviertan en impensables facilita no solo la guerra sino la humillación como práctica social de discriminación e impide, también, el duelo por la pérdida de sus vidas, pues los marcos que excluyen la posibilidad de lamentar públicamente la pérdida de algunas vidas (Butler, 2011, pp. 24-28) operan no solo en la guerra sino en la detención indefinida, en la tortura y en la política de inmigración, es decir, operan a nivel social y político, lo que propicia prácticas socialmente toleradas de humillación, y con ellas del mal moral.

\section{Lenguaje e imaginarios deshumanizantes}

El punto de partida de las anteriores observaciones ha sido que la humillación, ya sea como acto, proceso o padecimiento, consiste en negar la dignidad igual que los derechos humanos demandan para todos, aunque con la limitación de circunscribir, ante todo, el goce de dichos derechos a la condición de "ciudadanía" anclada a 
algún territorio. Además, esta negación se experimenta como una experiencia compleja de sufrimiento que no se reduce a pérdida de derechos.

Pareciera una obviedad señalar que la humillación sea una forma de mal moral como lo indica el título de este artículo, pero justamente lo que tendemos a juzgar como una obviedad señala algo que puede ser tan familiar que, dados sus efectos, precisa ser reconsiderado. Precisamente este es el punto que quiero subrayar: que el peligro de la humillación como práctica social estriba en que tiende a hacerse aceptable, justificable, regular. De ahí la necesidad de revisar críticamente los prejuicios que en muchos casos se alegan para negar el principio normativo de la dignidad humana, como sucede, por ejemplo, cuando las instituciones no respaldan el cumplimiento de un derecho, ${ }^{8}$ negando así autonomía y capacidad de decisión a quienes se ven impedidos para reclamarlos efectivamente. Y la necesidad, también, de encontrar razones para resistir la deshumanización que en ella opera.

Pues la humillación se refiere a las muchas maneras en que puede no ser respetada, vulnerada y no reconocida la dignidad humana. A lo largo de La sociedad decente, Margalit (2010) señala que la humillación se relaciona conceptualmente con dignidad, respeto, integridad, estima, autorrespeto, autoestima, crueldad, identidad, rechazo, comunidad moral. Humillación es toda conducta que dé razones a quien la sufre para sentir y reconocer que su dignidad está siendo irrespetada, pues el respeto es la manifestación externa de la dignidad. Margalit añade un aspecto problemático al análisis de la humillación: pues como espectadores podemos reconocer que un tipo de acción padecida por otra persona o grupo de personas es humillante, sin que esa persona o grupo afectado se sientan humillados, pues sus juicios de valor sobre la situación $x$ le(s) impide reconocer dicha acción como humillante. Margalit (2010, pp. 40-44) se refiere al caso de un hombre negro y esclavo que aunque es constantemente maltratado y humillado (Tío Tom), no se siente

8 Por ejemplo, como sucede en nuestro contexto cuando se restringe e impide el derecho al aborto en los tres casos admitidos por la legislación colombiana: cuando el embarazo es producto de violación, cuando representa peligro para la salud de la madre y cuando hay malformaciones genéticas en el feto que hacen inviable su vida fuera del útero. 
humillado debido a sus creencias religiosas, aunque sabe que así "no deben ser tratados los hijos de Adán”. De ahí que la humillación sea una contrapartida del discurso sobre la dignidad humana, siendo la dignidad el respaldo normativo y moral, a su vez, del discurso sobre los derechos humanos (Habermas, 2010, pp. 6-11).

Desde el punto de vista de la relación entre la interiorización de discursos sobre la dignidad y los derechos, y sobre las situaciones en que éstos son negados, podemos imaginar el caso de una persona inmersa en "imaginarios sociales" en los cuales la dignidad solo se adscribe diferencialmente: es decir, a unos sujetos sí y a otros no. En estos casos es obvio que se cultiva el respeto moral, pero solo para algunos, y con ello se consiente la posibilidad de humillar a aquellos con quienes no se reconocen compromisos u obligaciones morales y jurídicas, porque no se les considera como humanos en un sentido pleno.

Con "imaginarios sociales" me refiero, por ejemplo, a narraciones que hacen posible percibir algunas vidas, dentro de una misma sociedad, como una amenaza (respecto de algún ideal de nación), o como vidas desechables, ya sea por diferencias culturales, o porque contrarían patrones de normalidad dominantes. Vale la pena retomar algunos apartados de un texto del sitio web de Aryan Nations, citado por Sara Ahmed (2015, p. 77):

Las profundidades del amor están enraizadas, y muy profundamente, en el alma y el espíritu de un verdadero Nacionalista blanco; ninguna forma de "odio" podría comparársele. Por lo menos no un odio motivado por un razonamiento sin fundamentos. No es odio lo que hace que un hombre Blanco promedio mire a una pareja interracial con un ceño en la frente y aversión en su corason [sic] [...]. No es odio lo que lleva al trabajador Blanco a maldecir por el último bote de inmigrantes aventado en nuestras costas a los que se va a dar trabajo antes que a los ciudadanos Blancos que construyeron esta tierra [...] No, no es odio. Es amor.

Estos imaginarios sociales (historias y narrativas articuladas socialmente) circulan, como señala Sara Ahmed (2004, pp. 119-124), por medio de la carga cognitiva y afectiva de las emociones, como sucede, por ejemplo, con lo que ella llama "la organización del odio", que alinea el cuerpo del inmigrante con la figura del ladrón o del criminal. Ahmed (2015, pp. 80-87) muestra que el lenguaje del odio incita 
socialmente al odio y al crimen de odio y que el odio es una emoción que establece un vínculo negativo con una idea, una subjetividad, un cuerpo, al que se atribuye un rasgo o característica que se percibe como una amenaza, por ejemplo, de contaminación (como en el caso del racismo), pero también se percibe como una amenaza ante el disfrute de bienes, propiedades y derechos que definen una forma de vida, como la del ciudadano blanco, en la cita anterior.

Por mi parte señalo que tal puede ser también el caso del miedoodio ante sujetos cuyas formas de vida no encarnan patrones heteronormativos en su orientación sexual y en la conformación de una familia. En esta perspectiva de análisis resultan muy pertinentes las observaciones de Sara Ahmed (2015), porque al basarse en casos concretos permite entender que el contenido de los imaginarios sociales depende de la economía afectiva de las emociones, pues a través del lenguaje que apela a ellas circulan narraciones y se articulan imaginarios sociales que a causa de su repetición inciden en dinámicas sociales como las hasta ahora descritas.

Recapitulando, la pregunta por la humillación como un caso del mal moral socialmente tolerado, nos lleva a considerar dos aspectos:

1. El escenario amplio de negación de la dignidad. Las violaciones y prácticas de negación de la dignidad no se restringen a casos de violencia extrema como tortura, masacre, violación, sino que atraviesan diversas maneras o prácticas sociales que consisten en considerar a los otros de manera deshumanizadora, rechazando su valor y capacidad de agencia moral, es decir, su capacidad para actuar responsablemente.

2. Los afectos y la capacidad de respuesta moral. La humillación implica tres elementos en los cuales podemos ahondar para comprender la normalización del mal: me refiero al que es humillado, al que humilla y al espectador.

Un espectador que solo responde de manera sensacionalista manifiesta únicamente un rechazo momentáneo ante el horror, ante la exclusión, o ante la negación de las libertades; pero no responde críticamente, no es interpelado y, en ausencia de esta actitud crítica, aprende a considerar como normal los tratos humillantes y la negación de libertades civiles y de otros derechos, lo que contribuye a 
normalizar prácticas de deshumanización manifiestas socialmente en formas de exclusión que comienzan justo cuando se asiente en juzgar otras formas de vida, a otros seres humanos, como infrahumanos.

En este sentido, preguntarse por la humillación como práctica, por las emociones con que respondemos ante ella en sociedades cuya vida moral ha sido erosionada por la violencia, puede ser una vía para entender los efectos de la guerra sobre el patrimonio emocional que sustenta nuestra capacidad para vivir juntos; dicho de otra manera, para entender los efectos de la guerra sobre nuestra capacidad de respuesta moral.

Diversos autores han señalado cómo los contextos y las situaciones disponen fácilmente a individuos corrientes (no enfermos, ni especialmente sádicos) a la desindividuación, a la conducta grupal y a la deshumanización (De Swaan, 2016, pp. 87-114). Esto es lo que Philip Zimbardo (2008, pp. 36-37) llama "fuerzas situacionales" refiriéndose, por ejemplo, al uso de "etiquetas" (por ejemplo, llamar a otros "cucarachas"). Para ilustrarlo, menciona el caso del genocidio en Ruanda, donde recurrir a etiquetas contribuyó a tratar a los demás como entes abstractos: pues aplicar un término deshumanizador como "cucarachas" representaba algo que era necesario exterminar.

Al respecto, en El efecto Lucifer. El porqué de la maldad, dice Zimbardo: "Aquí tenemos un documento vivo de la imaginación hostil que pinta los rostros del enemigo con matices odiosos y luego destruye la tela" (2008, p. 38). Y agrega que: "La deshumanización es como una catarata en el cerebro que nubla el pensamiento y niega a otras personas su condición de seres humanos. Hace que esas otras personas lleguen a verse como enemigos merecedores de tormento, tortura y exterminio" (2008, p. 20).

Respecto del uso de etiquetas, es oportuno mencionar, en la perspectiva señalada, Poder y desaparición. Los campos de concentración en Argentina (2006) de la profesora Pilar Calveiro. En su libro, la profesora Calveiro (2006, pp. 34 y ss.) describe la lógica de funcionamiento de los campos en Argentina (lugares donde fueron concentrados quienes durante la dictadura fueron secuestrados, torturados, masacrados y desaparecidos), mostrando el papel que las etiquetas cumplen en la distribución de tareas fijamente establecidas que convierte a cada subgrupo en la pieza de un engranaje en el 
que nadie es responsable: están las patotas (los que recogían, los que chupaban o secuestraban), los grupos de inteligencia (los que orientaban el "interrogatorio", las torturas), los guardias (encargados de la disciplina y el trato cruel, convencidos de que los "chupados" eran todos "subversivos", es decir, "menos que hombres"), y estos últimos se encargaban también de "entregar los paquetes" a otro subgrupo, los desaparecedores de cadáveres, que los fusilaban en los centros de detención, o los trasladaban a otro lugar, o hacia los aviones desde donde eran arrojados al mar.

Es notable cómo el uso de las palabras-etiquetas oscurecía lo que allí sucedía: no se hablaba de "torturas" sino de "interrogatorio", no se hablaba de "prisioneros" sino de "paquetes", de "chupados", los "menos que hombres".

Los autores mencionados coinciden en que en estos escenarios hay que juzgar tanto responsabilidades individuales como estructurales, formas de pensamiento, políticas que disponen a que sea fácil deshumanizar y degradar a otros (De Swaan, 2015). En "La tortura y la ética de la fotografía: pensar con Sontag”, Butler (2010, pp. 107109, 115-124) también apunta en esta dirección al mostrar que en la tortura que exhiben las fotografías de Abu Ghraib juegan un papel preponderante las políticas públicas que defendió Estados Unidos en su guerra contra Irak, los imaginarios sociales y racistas sobre la idea de civilización, y la percepción de la cultura musulmana como una amenaza; pero también jugaron un papel lesivo los medios de comunicación al servicio del Estado y el Departamento de Defensa, que ella describe como "periodismo incorporado" (Butler, 2010, pp. 96-98, 105, 121). Estos factores crean marcos de interpretación y de representatividad de la realidad que excluyen ciertos fenómenos e incluyen otros, y permean, interpretando, lo que se muestra. De ahí que se pueda admitir que las prácticas de humillación que muestran las fotos de Abu Ghraib atentan no solo contra individuos, sino también contra aquello que los identifica, su cultura, y esto se manifiesta en la crueldad y el daño causado al cuerpo.

En este sentido, encontramos un rasgo común que propicia tanto la indiferencia moral del agente del daño y del espectador ante el sufrimiento, como la consecuente incapacidad para responder ante el daño: me refiero a la percepción de las personas como objetos. Pues 
los imaginarios que permean la percepción, y limitan la respuesta afectiva ante el daño, parten de ver a otros seres humanos como menos que humanos, como si fuesen objetos, aun a sabiendas de que son otros seres humanos, solo que se perciben como infrahumanos.

En la representación del cuerpo como un objeto, que subyace a las prácticas de humillación, reside una de las claves para imaginar cómo sería posible darle contenido concreto al principio de "dignidad": me refiero al cuerpo, pues situando la dignidad en el cuerpo y no en la tenencia de propiedades abstractas, se tiende a admitir nuestra recíproca vulnerabilidad ante el daño. ¿Por qué? Porque el sufrimiento que experimenta el cuerpo nos recuerda que somos vulnerables, finitos, expuestos a otros; el cuerpo nos recuerda que necesitamos condiciones que hagan posible, viable e inteligible la propia vida; nos recuerda que estamos expuestos de manera no voluntaria al dolor por la cercanía con otros cuerpos (Ahmed, 2015, pp. 51-60).

Como aspecto primario de una reflexión sobre la dignidad, el cuerpo permite considerar una experiencia común: la experiencia de estar expuestos ante el mundo nos recuerda que necesitamos condiciones concretas para que nuestra vida sea posible (Butler, 2006b; 2010). Desde esta perspectiva, el cuerpo permite situar la dignidad en un escenario diferente del lugar donde la sitúa el hecho de apelar a principios normativos universales como la racionalidad, la autonomía y la libertad radical, considerados como rasgos invulnerables y definitorios de nuestra humanidad, aunque la experiencia contraria que pone en escena el mal moral muestre lo contrario.

\section{Percibir a los otros como si fuesen objetos. La necesidad de comprender la dignidad desde el cuerpo}

La comprensión del cuerpo como objeto permite ver a los otros como objetos de uso y de cambio. Desde ese punto de vista, el cuerpo se representa como una entidad secundaria e irrelevante en la construcción de la humanidad. Aunque, recordando las palabras de Sofsky arriba citadas: "[...] el cuerpo no es una parte del hombre, sino su centro constitucional. Por eso el daño afecta por igual al alma y al espíritu, al yo y a la existencia social" (2006, p. 65). 
Incluir las emociones y el sufrimiento para comprender el daño que produce la humillación es devolver la comprensión de la dignidad humana al terreno del cuerpo. ¿Por qué? Justamente porque "la deshumanización depende de discursos negativos sobre el cuerpo, así como de construcciones filosóficas sobre el sujeto humano como desencarnado" (Oliver, 2011, p. 94), es decir, como si el sujeto humano no tuviera carne, ni cuerpo. ${ }^{9}$ Esta perspectiva de revisar nuestras concepciones sobre la dignidad situando al cuerpo en el centro de la reflexión, también la encontramos en Judith Butler (2010, pp. 43-56), con su propuesta de pensar la precariedad (precariousness), la vulnerabilidad y exposición no elegida, característica de toda vida; así como en Elaine Scarry (1985, pp. 19-20, 29, 31, 33, 35-38), quien aborda el sufrimiento infligido al cuerpo como una manera de deshacer el mundo y la propia subjetividad. Indagar por la dignidad desde el cuerpo, permite notar, como enfatiza Sophie Oliver (2011, p. 95), cuán problemático es considerar la dignidad humana como una cualidad desencarnada, pues de esa manera es difícil reconocer que la negación de la dignidad, presente en toda experiencia de humillación, consiste, precisamente, en la experiencia del sufrimiento y no solo en la negación, suspensión o violación de derechos: de ahí que "sea imperativo reconocer la posición del cuerpo dentro de procesos y narrativas de deshumanización" (Oliver, 2011, p. 95).

El sufrimiento involucrado en la humillación consiste en una experiencia primaria básica de la vulnerabilidad y de la fragilidad que también puede ser potenciada socialmente, como sucede con los escenarios donde tiene lugar la humillación social, que he intentado mostrar como una forma socialmente tolerada del mal moral. Ahora bien, en respuesta a las situaciones de humillación en el espacio del mundo social, una vía para reconocer el lugar central del cuerpo cuando se intenta pensar cuáles sean las condiciones materiales concretas del respeto de la dignidad humana, son los relatos y testimonios de personas que han padecido la experiencia de la deshumanización y han encontrado vías para oponerse y resistir a la lógica de la deshumanización.

De ahí la relevancia de lo que señala Sophie Oliver (2011, pp. 93-96) cuando afirma que el dualismo entre cuerpo y alma es la base

9 La traducción de las citas de Sophie Oliver es de mi autoría. 
sobre la que la modernidad ha construido la subjetividad. Considerar el papel del dualismo es relevante para intentar juzgar críticamente nuestros criterios de "normalidad" y de "lo humano", es decir, la manera como se establecen criterios normativos de lo humano que propenden por darle valor a unas vidas por encima de otras. Esto permite entender por qué muchos grupos e individuos han sido históricamente asociados con símbolos que encarnan lo despreciable e incluye a "víctimas de atrocidades deshumanizadoras cuyos cuerpos traumatizados al no ajustarse a las normas establecidas, marginados, amenazan con romper las matrices ontológicas y epistemológicas, en los límites o márgenes a los cuales han sido violentamente empujados" (Oliver, 2011, p. 94).

Por supuesto, la dificultad de ver a los otros como subjetividades con cuerpo responde justamente al planteamiento abstracto de la dignidad, que suele interpretarse como un valor metafísico e inviolable. Sophie Oliver (2011, p. 96) indica que la dignidad puede ser considerada no solo como un valor intrínseco pre-dado, sino también como una aspiración que demanda condiciones materiales para su concreción. Por eso desde este enfoque importa analizar los casos en los que la dignidad es negada, referidos a personas concretas que sienten y padecen dolor y sufrimiento debido a que han sido y son objetos de diversos tipos de violencia.

Oliver (2011, p. 95) indica que tanto en la moral como en el derecho se plantea la dignidad en términos abstractos o inmateriales: de ahí que una paradoja fundamental del discurso de los derechos humanos sea su intento por proteger la dignidad, en términos abstractos, partiendo de una igualdad universalizable. La atribución de igualdad parece suponer una condición metafísica fundamental que no experimentamos en la vida concreta con los otros. En esa medida, la misma autora (2011, p. 94) indica que el discurso de los derechos humanos también es un discurso incorpóreo, pues el sujeto de los derechos humanos no tiene cuerpo. Proteger a los seres humanos exigiría, en primer lugar, proteger sus cuerpos, su corporalidad. Esto puede interpretarse como la necesidad de responder a sus necesidades materiales concretas; proteger su vulnerabilidad, que nos recuerda la propia; proteger sus condiciones particulares de vida, sus bienes extrapatrimoniales (afectos), no solo 
los patrimoniales: en suma, implica un cuidado de la vida en común, pero de una manera históricamente situada, es decir, atendiendo a situaciones y a contextos concretos.

\section{Conclusiones parciales y asuntos pendientes}

Cualquier intento de resistir ante la deshumanización, de oponerse a las prácticas que la fomentan, tiene que reconocer la corporeidad del sujeto humano (Oliver, 2011, pp. 95-96), y cómo a través de discursos se materializan los cuerpos (Butler, 2006b). Dicho con Ahmed (2015): cómo los cuerpos emergen al mismo tiempo como superficies separadas y vinculadas a través de emociones como el odio, el miedo, la repugnancia, la vergüenza y el amor. Que los cuerpos emergen a través de discursos que los producen como cuerpos odiados, despreciables o temidos, es un planteamiento novedoso que convierte en una exigencia la pregunta por el significado de pensar la dignidad desde el cuerpo, por cómo entender la motivación moral para defender su respeto recíproco y para proponer caminos posibles para repensar, más allá del deber, el carácter de la obligación recíproca del respeto moral (es decir, de la dignidad). En esta dirección resulta pertinente explorar una vía de análisis que partiendo de la experiencia del mundo que el cuerpo nos ofrece, incluya el efecto de las emociones y del lenguaje cargado de emociones en las dimensiones social y política de la vida humana.

Por tanto, la exigencia de pensar la dignidad desde el cuerpo estriba en que "para defender la dignidad humana, o para reconocer las prácticas de humillación y su papel en nuestra sociedad actual, es necesario hacer algo más que atribuir a los otros cualidades abstractas como la autonomía, la personalidad o la dignidad" (Oliver, 2011, p. 95). Justamente, esas propiedades que otros autores denominan identidad, pertenencia a una comunidad, autodeterminación, agencia moral y autoconciencia, las cuales se asumen como garantizadas o pre-dadas ahistóricamente. Categorías abstractas como las mencionadas, descuidan situar históricamente la reflexión sobre la dignidad humana y dificultan el ejercicio de resistir la deshumanización.

Resistir la deshumanización, es decir, identificar cómo influye en nuestro trato diario, en nuestra percepción de los otros y en nuestra capacidad de respuesta moral, exige ampliar los márgenes de nuestra 
comprensión de la condición humana, cuestionando, por ejemplo, la posesión de cualidades abstractas e innatas cuyo suelo es un modelo dualista (alma-mente/cuerpo) de la condición humana. En suma, resistir la deshumanización exige no identificar a la humanidad con atributos abstractos adjudicados de manera excluyente. Esto es lo que expresan algunos autores como Judith Butler $(2006,2010,2011)$ al apelar en sus discusiones a propiedades mínimas en el sentido de básicas y compartidas por toda forma de vida, como la "precariedad".

Además, examinar el menoscabo de la dignidad en escenarios donde su privación se analiza en los términos del mal moral, como sucede con la humillación en el ámbito social, permite reconocer que la dignidad no solo es violada en el escenario de acciones crueles y atroces (Card, 2010). En la vida social encontramos maneras "sofisticadas" de negarla, como en el caso de la precariedad políticamente inducida (precarity),10 definida por Butler (2010, p. 16) como una noción eminentemente política consistente en una "asignación diferencial de precariedad", como si unas vidas fuesen más vulnerables que otras. Esa atribución diferencial de precariedad establece una distancia entre el propio sentido de la dignidad y la dignidad débil y vulnerable de los otros. Como dice Butler (2010, pp. 46-47):

La precariedad [precarity] designa esa condición políticamente inducida en la que ciertas poblaciones adolecen de falta de redes de apoyo sociales y económicas y están diferencialmente más expuestas a los daños, la violencia y la muerte. Tales poblaciones se hallan en grave peligro de enfermedad, pobreza, hambre, desplazamiento y exposición a la violencia sin ninguna protección. La precariedad [precarity] también caracteriza una condición políticamente inducida de la precariedad [precariousness], que se maximiza para las poblaciones expuestas a la violencia estatal arbitraria que, a menudo, no tienen otra opción que la de apelar al Estado mismo contra el que necesitan protección. En otras palabras, apelan al Estado en busca de protección, pero el Estado es, precisamente, aquello contra lo que necesitan protección.

10 Para Butler (2010, p. 46), las dos acepciones de precariedad (precariousness / precarity) están interconectadas porque "las vidas son por definición precarias [precarious]: pueden ser eliminadas de manera voluntaria o accidental, y su persistencia no está garantizada de ningún modo. En cierto sentido, es un rasgo de toda vida, y no existe una concepción de la vida que no sea precaria [precarious], salvo, por supuesto, en la fantasía, y en particular en las fantasías militares". 
Concluyo parcialmente estas observaciones recapitulando, en diálogo con los autores y autoras mencionados, algunos caminos posibles para continuar con la indagación: primero, la necesidad de repensar la dignidad desde una concepción corporal de humanidad, la cual alude a una perspectiva históricamente situada, que subraya cómo las prácticas de deshumanización consistentes en limitar el ámbito de nuestras obligaciones morales con otros (Oliver, 2011, p. 89) producen sufrimiento y exigen considerar la relación intrínseca entre cultura, contextos sociales y políticos, y las necesidades y exigencias de grupos concretos que han sufrido daño. Este enfoque quizá pueda contribuir a identificar las condiciones materiales que exige una reflexión crítica sobre la dignidad humana, y ayudar a resistir ante la facilidad de deshumanizar y degradar a otros seres humanos. Quizá el primer paso sea no dar por sentado que somos subjetividades autónomas, libres, y capaces de agencia moral, sino recordar que estas son ideas reguladoras que para poder concretizarse dependen de condiciones materiales, históricas, específicas y contextuales que incluyen la complejidad de la experiencia humana del mundo entre los otros y en un mundo social organizado basado en diferentes tipos de dispositivos (Agamben, 2015, pp. 9-34).

Pero ¿qué significa esto? En la línea de las autoras con cuya obra hemos dialogado hasta el momento (Butler, Ahmed, Oliver), esto exige considerar al cuerpo como eje de nuestra experiencia del mundo que dota de significado al "alma", e incluye, además del movimiento del pensar, la experiencia del dolor, del sufrimiento y de las emociones. Estos aspectos de nuestra corporalidad remiten a una experiencia del mundo que no puede reducirse a una experiencia privada, ni tampoco a una experiencia cuyo significado solo sea entendible en términos cognitivos, sociales o políticos.

Además, con su carga afectivo-cognitiva, las emociones no solo producen fronteras sino que son la clave para deshacerlas, pues "lo que nos separa de otros también nos conecta con otros" (Ahmed, 2015 , p. 54). En relación con los temas planteados, esto significa que las emociones pueden tanto ampliar como restringir, según el caso, nuestra capacidad de respuesta moral ante el daño que produce la deshumanización implícita en las prácticas de humillación; y también son claves para analizar nuestra capacidad para deshacer su posibilidad. 
Considero que esta posibilidad nos permite dialogar con lo que afirma Sophie Oliver (2011, pp. 95-96) respecto de materializar en el cuerpo la dignidad:

Si la dignidad está materializada en el cuerpo, entonces incluye placer y sufrimiento, belleza y enfermedad, fuerza y vulnerabilidad, vida y muerte. Si la dignidad es corporalizada entonces es tanto local como universal; siempre situada, y no puede ser entendida como distinta del individuo que la lleva, y cualquier defensa de la dignidad tiene que reconocer la especificidad de la circunstancia de un individuo o de un grupo que emerge alrededor de un conjunto de reclamaciones compartidas. Respetar la dignidad materializada en el cuerpo de un ser humano es primero y ante todo un acto de reconocimiento: reconocer como humano cada aspecto de su experiencia, pese a lo abyecto y extraño (extranjero) que pueda parecer; reconocer la especificidad de su persona, y al hacerlo afirmar el lugar del otro junto al yo (self) dentro de la comunidad humana.

Ahora bien, ¿cómo cultivar esta forma de percepción? Es decir, ¿cuáles serían las medidas concretas materializables para incitar a tal forma de percepción? No hay respuestas definitivas, pero sí indicios. Una vía posible puede ser abriendo espacios de reflexión para escuchar, para intentar comprender -con las limitaciones cognitivas que supone dejarse afectar por el dolor de los otros, sin poder apropiárnoslo- las consecuencias y las secuelas de los procesos y prácticas deshumanizantes, a través de los testimonios de quienes se han convertido en objetivo de procesos deshumanizantes (Ahmed, 2015, pp. 69-76).

Esto exige asistir a la humanidad concreta e individual del que sufre, y reclamar su inclusión dentro de la comunidad humana. Esto es: reconocerlo como sujeto, reclamar su protección y cuidado. Este reconocimiento del sufrimiento de aquellos que han sido excluidos es vital porque de él depende nuestra humanidad, es decir "nuestra capacidad para actuar como seres moralmente responsables" (Oliver, 2011, p. 96).

Finalmente, en segundo lugar, queda pendiente cuestionar, desde el enfoque que sitúa la dignidad en el cuerpo, los límites de una política del dolor, manifiestos en el punto donde comienza la fetichización de la herida. Tanto Ahmed como Lauren Berlant 
señalan las limitaciones de convertir la identidad traumática en el centro de una política sentimental. Ahmed (2015, pp. 65-76) plantea la necesidad de rechazar convertir el dolor del otro en mercancía o en parte de una sociedad del espectáculo, en la que el dolor es comparable a un objeto que puede ser comprado o convertido en una mercancía y por tanto reivindicado como propio porque se asume que se puede conocer y experimentar como si fuera propio, a costa, por supuesto, de olvidar la historia que le precede. Por eso enfatiza en que la política de una respuesta ética y política ante el dolor debe partir de la imposibilidad de conocer con certeza el dolor de los otros, y de la imposibilidad de sentir su experiencia dolorosa, de evitar apropiarse de dicha experiencia como si se tratase de un objeto. De ahí la necesidad de no soslayar la historia concreta de dolor de quienes han sufrido daño, de quienes han sufrido la discriminación y la negación de una forma de vida en nombre, por ejemplo, de una política de asimilación cultural y de un ideal de nación reconciliada -como en el caso de la generación robada de Australia (Ahmed, 2015, pp. 68-72). Por su parte, Lauren Berlant (2011, p. 58) afirma, también críticamente, que la politización del dolor no necesariamente transforma las "estructuras hegemónicas de la normatividad y del duelo", y que "la reparación del dolor no acarrea consigo una vida justa" 


\section{Referencias}

Aceptan delito de discriminación en caso de estudiante Sergio Urrego. (2016, octubre 12). El Tiempo [en línea]. Recuperado de https://bit. $1 y / 2 s S X E b z$

Agamben, G. (2015). ¿Qué es un dispositivo? Seguido de El amigo y de La iglesia y el reino (M. Ruvitoso, Trad.). Barcelona: Anagrama.

Ahmed, S. (2004). Affective Economies. Social Text 79, 22(2), 117-139. Recuperado de https://bit.ly/2JF1mvA

Ahmed, S. (2010). The Promise of Happiness. Durham [NC]: Duke University Press.

Ahmed, S. (2015). La política cultural de las emociones (C. Olivares M., Trad.). México: Universidad Nacional Autónoma de México. Programa universitario de estudios de género.

Álvarez Vigaray, R. (1966). La responsabilidad por daño moral. ADC, 82116.

Anderson-Gold, S. \& Muchnik, P. (2010). Kant's Anatomy of Evil. Cambridge: Cambridge University Press.

Arendt, H. (1999). Eichmann en Jerusalem (C. Ribalta, Trad.). Barcelona: Lumen.

Arendt, H. (2006). Los orígenes del totalitarismo (G. Solana, Trad.). Madrid: Alianza.

Arendt, H. (2007). Responsabilidad y juicio (M. A. Candel y F. Birulés, Trads.). Barcelona: Paidós.

Berlant, L. (2011). El corazón de la nación. Ensayos sobre política y sentimentalismo (V. Schussheim, Trad.). México: F. C. E.

Bernstein, R. (2005). El mal radical. Una indagación filosófica (M. G. Burello, Trad.). Argentina: Editorial Lilmod.

Bernstein, R. (2015). Violencia. Pensar sin barandillas (S. Rey Salamanca, Trad.). Barcelona: Gedisa.

Brison, S. (2003). Aftermath. Violence and the Remaking of a Self. Princeton: Princeton University Press.

Butler, J. (2002). Cuerpos que importan. Sobre los límites materiales y discursivos del "sexo" (A. Bixio, Trad.). Buenos Aires: Paidós.

Butler, J. (2006a). Vida precaria: el poder del duelo y la violencia (F. Rodríguez, Trad.). Buenos Aires: Paidós. 
Butler, J. (2006b). Deshacer el género (P. Soley-Beltrán, Trad.). Barcelona: Paidós.

Butler, J. (2010). La tortura y la ética de la fotografía: pensar con Sontag. En Marcos de guerra. Las vidas lloradas (pp. 95-146). Madrid: Paidós.

Butler, J. (2011). Violencia de Estado, guerra, resistencia. Por una nueva política de la izquierda (P. Soley-Beltran, Trad.). Barcelona: Katz.

Calveiro, P. (2006). Poder y desaparición. Los campos de concentración en Argentina ( $1^{\underline{a}}$ ed., $3^{\underline{a}}$ reimp.). Buenos Aires: Colihue.

Card, C. (2002). The Atrocity Paradigm. A Theory of Evil. Cambridge: Cambridge University Press.

Card, C. (2010). Confronting Evils. Terrorism, Torture, Genocide. Cambridge: Cambridge University Press.

De Swaan, A. (2015). Dividir para matar. Una exploración de la mentalidad genocida (C. Holguín, Trad.). Bogotá: Semana Libros.

Domínguez, E. (2003). El daño moral: intento de concretización de un concepto. Anuario da Facultade de Dereito da Universidade da Coruña, 7, 263-270. Recuperado de https://bit.ly/2JK4hTK

Fernández Arregui, S. (2008). Reflexiones sobre el significado social de la humillación. Psicología Política, 37, 29-46. Recuperado de https://bit. $1 \mathrm{y} / 216 \mathrm{mtMZ}$

Habermas, J. (2010). El concepto de dignidad humana y la utopía realista de los derechos humanos. Dianoia, 55(64), 3-25. Recuperado de https:// bit.ly/2jH23j7

Henao, J. C. (1998). El daño. Análisis comparativo de la responsabilidad extracontractual del Estado en derecho colombiano y francés. Bogotá: Universidad Externado de Colombia.

Kant, I. (1969). La religión dentro de los límites de la mera razón (F. Martínez, Trad.). Madrid: Alianza.

Lindner, E. (2009). Emotion and Conflict: How Human Rights Can Dignify Emotion and Help Us Wage Good Conflict. Westport, CT: Greenwood Publishing Group.

Margalit, A. (2010). La sociedad decente (C. Castells Auleda, Trad.). Barcelona: Paidós.

Navia Arroyo, F. (2007). Daño moral, daño fisiológico y daño a la vida de relación en Colombia. Revista de Derecho Privado, 12-13, 289-305. Recuperado de https://bit.ly/2JJWR6m 
Neiman, S. (2012). El mal en el pensamiento moderno. Una historia no convencional de la filosofía (F. Garrido, Trad.). México: F. C. E.

Nussbaum, M. (2006). El ocultamiento de lo humano. Repugnancia, vergüenza y ley (G. Zadunaisky, Trad.). Buenos Aires: Katz.

Oliver, S. (2011). Dehumanization: Perceiving the Body as (In)Human. In P. Kaufmann, H. Kuch, C. Neuhäusser \& E. Webster (Eds.), Humiliation, Degradation, Dehumanization. Human Dignity Violated (pp. 85-97). Dordrecht: Springer.

Pía Lara, M. (2009). Narrar el mal: una teoría posmetafísica del juicio reflexionante. Barcelona: Gedisa.

Pía Lara, M. (2011). Rethinking Evil. Contemporary Perspectives. Berkeley: University of California Press.

Revault d'Allones, M. (2010). Lo que el hombre hace al hombre. Ensayo sobre el mal político (H. Pons, Trad.). Buenos Aires: Amorrortu.

Scarry, E. (1985). The Body in Pain. The Making and Unmaking the World. New York: Oxford University Press.

Sofsky, W. (2006). Tratado sobre la violencia (J. Chamorro Mielke, Trad.). Madrid: Abada.

Velásquez Posada, O. (2009). Itinerario jurisprudencial del daño moral en Colombia [Archivo DocPlayer]. Recuperado de https://bit.ly/2JLNCTj

Vielma Mendoza, Y. (2001). Una aproximación al estudio del daño moral extracontractual (Ponencia). II Congreso Nacional de Responsabilidad Civil y Seguro, Córdoba, España, 3 y 4 de Mayo de 2001. Recuperado de https://bit.ly/2t3ArCS

Vielma Mendoza, Y. (2006). Discusiones en torno a la reparación del daño moral. Dikaiosyne, 16, 137-156. Recuperado de https://bit.ly/2HKc1mW

Zimbardo, P. (2008). El efecto Lucifer. El porqué de la maldad (G. Sánchez Barberán, Trad.). Barcelona: Paidós. 